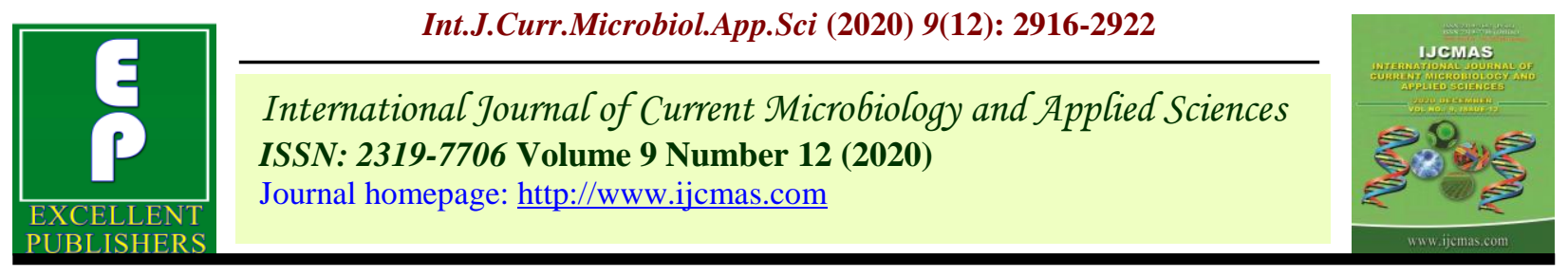

Original Research Article

https://doi.org/10.20546/ijcmas.2020.912.346

\title{
Evaluation of Biostimulants in Growbag Culture of Organic Amaranthus (Amaranthus tricolor L.)
}

\author{
A. Sherinlincy ${ }^{*}$, M. Rafeekher and S. Sarada \\ Department of Vegetable Science, College of Agriculture, Kerala Agricultural University, \\ Vellayani-695522, Trivandrum, India \\ *Corresponding author
}

\section{A B S T R A C T}

\section{Keywords}

Amaranthus

tricolor,

Biostimulant,

Humic-fulvic acid

mixture

Article Info

Accepted:

18 November 2020

Available Online:

10 December 2020

\begin{abstract}
An experiment was conducted to evaluate the effect of biostimulants under different application methods in grow bag cultivation of organic amaranthus. Foliar application and wick fertigation were the two methods of application under the study for which wick fertigation were installed using pvc pipes and glass wool wicks were used. Biostimulants such as humic acid (3\%), humic acid fulvic acid mixture (3\%), moringa leaf extract (3\%), vermiwash (3\%), cow urine (ten times diluted), salicylic acid $\left(50 \mathrm{mgL}^{-1}\right)$ were compared with $\operatorname{RDF}(0.22: 0.11: 0.11 \mathrm{~g} / \mathrm{plant})$ and distilled water (control) at weekly intervals. Observations were recorded on different biometric characters $v i z$. plant height $(\mathrm{cm})$, leaves per plant, leaf length $(\mathrm{cm})$, leaf width $(\mathrm{cm})$, stem girth $(\mathrm{cm})$, branches per plant, root length $(\mathrm{cm})$, days to flowering, leaf/stem ratio, fresh weight of leaves per plant $(\mathrm{g})$, yield per cutting (g) and yield per plant $(\mathrm{g})$. Among the biostimulants, humic - fulvic acid mixture @ 3\% produced the highest plant height $(85.83 \mathrm{~cm})$, leaf length $(15.08 \mathrm{~cm})$, leaf width, branches per plant, fresh weight of leaves $(225.85 \mathrm{~g})$ and yield per plant $(646.01 \mathrm{~g})$.
\end{abstract}

\section{Introduction}

Amaranthus (Amaranthus tricolor L.) is an important leafy vegetable which is well known for its nutritive values like vitamins and minerals and also called as 'poor man's spinach'. In Kerala, amaranthus is cultivated in an area of 2061 ha (DES, 2017) and growbag culture is a recent trend which paves a way to meet the nutritional requirement of $125 \mathrm{~g}$ leafy vegetables per day/adult especially through urban farming but the major constraint associated with growbag culture is reduction in yield.
In vegetable production, plant biostimulants have been gaining interest due to improved yield, nutrient use efficiency, quality and abiotic stress tolerance. Biostimulant like humic substances also promote early growth, reduce mineral fertilizer application and hazardous effect of plant pathogens (Taha et al., 2016). Moringa leaf extract is a low cost and environment friendly biostimulant that can be used effectively for various crops due to its easy preparation, high nutritive and antioxidant effect (Abdalla, 2014). Salicylic acid can improve not only the yield but also bioactive compounds in leaf amaranth. 
Vermiwash can be used as foliar spray to increase yield and plant growth since nutrients are readily available for plants (Sundararasu, 2016). Cow urine is used for improving yield as well as quality.

However, different application methods influence the efficiency of biostimulants. Being a leafy vegetable foliar spray of these biostimulants may have limitations with regards to visual appearance and other organoleptic characters. Wick irrigation have been widely promoted and adopted as an efficient irrigation system for urban agriculture. High water use efficiency, less need for manpower, increase in uniformity and quality of productive, temperature control of the root system are the major advantages of this system (Ferrarezi and Testezlaf, 2016). In this context, present investigation is proposed to evaluate the effect of biostimulants under different application methods in organic growbag cultivation of amaranthus.

\section{Materials and Methods}

The present investigation entitled "Evaluation of biostimulants in growbag culture of organic Amaranthus (Amaranthus tricolor)" was carried out at the Department of Vegetable Science, College of Agriculture, Vellayani, during 2019 - 2020. The experimental site was located at about $8.5^{\circ}$ North latitude and $76.9^{\circ}$ East longitude, with an average altitude of $29.00 \mathrm{~m}$ above mean sea level. In the experiment, amaranthus variety Arun was raised in seed bed and transplanted 24 days after sowing to growbags. Experiments were laid out in CRD with two factors replicated thrice for evaluation of biostimulants and method of application. Foliar application and wick fertigation were the two methods of application under the study for which wick fertigation were installed using pvc pipes and glass wool wicks were used. Biostimulants such as humic acid (3\%), humic acid fulvic acid mixture (3\%), moringa leaf extract (3\%), vermiwash (3\%), cow urine (ten times diluted), salicylic acid $\left(50 \mathrm{mgL}^{-1}\right)$ were compared with RDF (0.22:0.11:0.11 g/plant) and distilled water (control) at weekly intervals (Table 1). Observations were recorded on different biometric characters viz. plant height $(\mathrm{cm})$, leaves per plant, leaf length $(\mathrm{cm})$, leaf width $(\mathrm{cm})$, stem girth $(\mathrm{cm})$, branches per plant, root length $(\mathrm{cm})$, days to flowering, leaf/stem ratio, fresh weight of leaves per plant $(\mathrm{g})$, yield per cutting $(\mathrm{g})$ and yield per plant $(\mathrm{g})$. In addition, pest and disease observations were also taken.

\section{Results and Discussion}

In the present study, significant variation was recorded for all the characters. Humic-fulvic acid mixture @ 3\% through foliar application significantly increased the height of plant $(85.83 \mathrm{~cm})$ (Table 2), leaf length $(15.08 \mathrm{~cm})$ and leaf width $(6.80 \mathrm{~cm})$ (Fig. 1). Vermiwash (a) 3\% through wick fertigation exhibited the highest number of leaves per plant (118.83) (Table 3). Humic - fulvic acid mixture @ 3\% through foliar application was also effective in increasing the branches per plant (11.66) while distilled water through wick fertigation recorded least number of branches per plant (4.66).

Longest root length $(34.16 \mathrm{~cm})$ was recorded when humic acid @ 3\% were applied through foliar application compared to control (18.66 $\mathrm{cm})$. Late bolting was recorded with humic acid@3\%, humic-fulvic acid mixture@3\% and RDF through foliar application. Earlier bolting was recorded in salicylic acid @ 50 $\mathrm{mgL}^{-1}$ through wick fertigation. Application of salicylic acid @ $50 \mathrm{mgL}^{-1}$ through wick fertigation significantly increased the leaf/stem ratio (0.50) which was at par with vermiwash @3\% through wick fertigation (0.45). 
The total fresh weight of leaves per plant was significantly higher (225.85g) for humic fulvic acid mixture @ 3\% followed by RDF and humic acid @ 3\%. At first, second and third harvest, significantly higher yield per cutting was recorded in ten times diluted cowurine (30.64g), RDF (171.62 g), humic fulvic acid mixture@ $3 \%$ (170.73g)through foliar application respectively while the lowest was recorded by distilled water through wick fertigation. Humic - fulvic acid mixture@3\% through foliar application also recorded highest yield per cutting (Fig. 2) and yield per plant $(646.01 \mathrm{~g})$ compared to distilled water through foliar application (180.72 g) (Table 4).

Table.1 Details of treatments in experiments

\begin{tabular}{|l|l|}
\hline \multicolumn{1}{|c|}{$\begin{array}{c}\text { Treatment } \\
\text { combinations }\end{array}$} & \multicolumn{1}{c|}{ Treatment details } \\
\hline $\mathbf{B}_{\mathbf{1}} \mathbf{M}_{\mathbf{1}}$ & Distilled water (control) through wick fertigation \\
\hline $\mathbf{B}_{\mathbf{2}} \mathbf{M}_{\mathbf{1}}$ & RDF through wick fertigation \\
\hline $\mathbf{B}_{\mathbf{3}} \mathbf{M}_{\mathbf{1}}$ & Humic acid commercial through wick fertigation \\
\hline $\mathbf{B}_{\mathbf{4}} \mathbf{M}_{\mathbf{1}}$ & Humic acid - fulvic acid mixture through wick fertigation \\
\hline $\mathbf{B}_{\mathbf{5}} \mathbf{M}_{\mathbf{1}}$ & Moringa leaf extract through wick fertigation \\
\hline $\mathbf{B}_{\mathbf{6}} \mathbf{M}_{\mathbf{1}}$ & Vermiwash through wick fertigation \\
\hline $\mathbf{B}_{\mathbf{7}} \mathbf{M}_{\mathbf{1}}$ & Cow urine through wick fertigation \\
\hline $\mathbf{B}_{\mathbf{8}} \mathbf{M}_{\mathbf{1}}$ & Salicylic acid through wick fertigation \\
\hline $\mathbf{B}_{\mathbf{1}} \mathbf{M}_{\mathbf{2}}$ & Distilled water (control) through foliar application \\
\hline $\mathbf{B}_{\mathbf{2}} \mathbf{M}_{\mathbf{2}}$ & RDF through foliar application \\
\hline $\mathbf{B}_{\mathbf{3}} \mathbf{M}_{\mathbf{2}}$ & Humic acid commercial through foliar application \\
\hline $\mathbf{B}_{\mathbf{4}} \mathbf{M}_{\mathbf{2}}$ & Humic - fulvic acid mixture through foliar application \\
\hline $\mathbf{B}_{\mathbf{5}} \mathbf{M}_{\mathbf{2}}$ & Moringa leaf extract through foliar application \\
\hline $\mathbf{B}_{\mathbf{6}} \mathbf{M}_{\mathbf{2}}$ & Vermiwash through foliar application \\
\hline $\mathbf{B}_{\mathbf{7}} \mathbf{M}_{\mathbf{2}}$ & Cow urine through foliar application \\
\hline $\mathbf{B}_{\mathbf{8}} \mathbf{M}_{\mathbf{2}}$ & Salicylic acid through foliar application \\
\hline
\end{tabular}

Table.2 Effect of biostimulants, method of application and their interaction on plant height

\begin{tabular}{|l|c|c|c|}
\hline \multirow{2}{*}{ Biostimulants } & \multicolumn{3}{|c|}{ Plant height (cm) } \\
\cline { 2 - 3 } & M1 & M2 & Mean B \\
\hline B1 & 57.50 & 43.96 & 50.73 \\
\hline B2 & 53.66 & 74.66 & 64.16 \\
\hline B3 & 61.66 & 71.26 & 66.46 \\
\hline B4 & 58.66 & 85.83 & 72.25 \\
\hline B5 & 62.33 & 55.50 & 58.91 \\
\hline B6 & 65.93 & 62.83 & 64.38 \\
\hline B7 & 60.16 & 60.16 & 60.16 \\
\hline B8 & 68.00 & 69.60 & 68.80 \\
\hline & 60.99 & 65.47 & \\
\hline SE m \pm & Biostimulants (B) & Method (M) & BXM \\
\hline CD $(\mathbf{0 . 0 5 )}$ & 3.844 & 1.922 & 5.436 \\
\hline
\end{tabular}


Table.3 Effect of biostimulants, method of application and their interaction on leaves per plant

\begin{tabular}{|l|c|c|c|}
\hline \multirow{2}{*}{ Biostimulants } & \multicolumn{3}{|c|}{ Leaves per plant } \\
\cline { 2 - 4 } & Method & Mean B \\
\hline B1 & 82.00 & 70.33 & 76.16 \\
\hline B2 & 93.33 & 105.66 & 99.50 \\
\hline B3 & 100.66 & 112.53 & 106.60 \\
\hline B4 & 110.00 & 116.15 & 113.07 \\
\hline B5 & 91.16 & 115.56 & 103.36 \\
\hline B6 & 118.83 & 116.83 & 117.83 \\
\hline B7 & 94.56 & 117.41 & 105.98 \\
\hline B8 & 96.33 & 94.33 & 95.33 \\
\hline Mean M & 98.36 & 106.10 & \\
\hline & Biostimulants (B) & Method (M) & BXM \\
\hline SE m士 & 1.955 & 0.977 & 2.764 \\
\hline CD (0.05) & 5.656 & 2.828 & 7.999 \\
\hline
\end{tabular}

Table.4 Effect of biostimulants, method of application and their interaction on yield per plant

\begin{tabular}{|l|c|c|c|}
\hline \multirow{2}{*}{ Biostimulants } & \multicolumn{3}{|c|}{ Yield per plant } \\
\cline { 1 - 3 } & M1 & Method & \multirow{2}{*}{ Mean B } \\
\cline { 1 - 3 } B1 & 228.71 & 180.72 & 204.71 \\
\hline B2 & 236.06 & 452.77 & 344.42 \\
\hline B3 & 208.23 & 392.03 & 300.13 \\
\hline B4 & 297.19 & 646.01 & 471.60 \\
\hline B5 & 255.19 & 253.20 & 254.20 \\
\hline B6 & 298.32 & 323.83 & 311.07 \\
\hline B7 & 246.21 & 388.02 & 317.11 \\
\hline B8 & 264.25 & 239.22 & 251.74 \\
\hline Mean M & 254.27 & 359.47 & \\
\hline & Biostimulants (B) & Method (M) & BXM \\
\hline SE \pm & 38.960 & 19.480 & 55.098 \\
\hline CD $(\mathbf{0 . 0 5 )}$ & 112.743 & 56.371 & 159.442 \\
\hline
\end{tabular}


Fig.1 Effect of biostimulants, method of application and their interaction on leaf length and leaf width of amaranthus

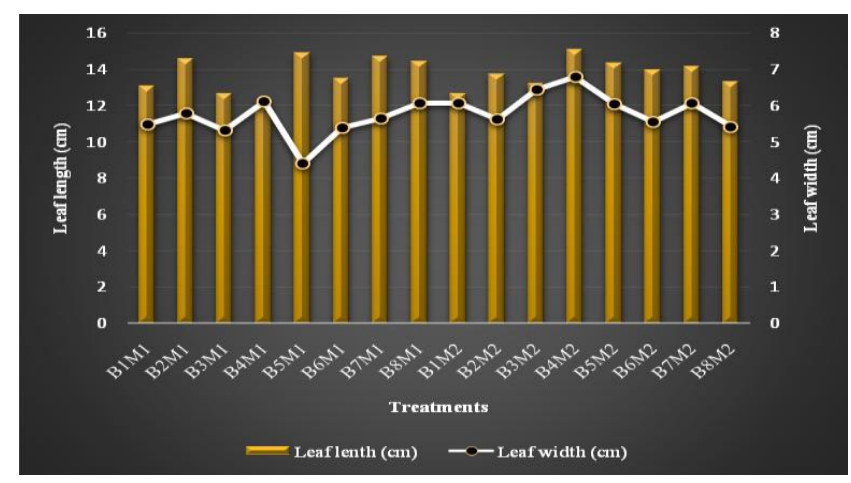

Fig.2 Effect of biostimulants, method of application and their interaction on yield per cutting of amaranthus

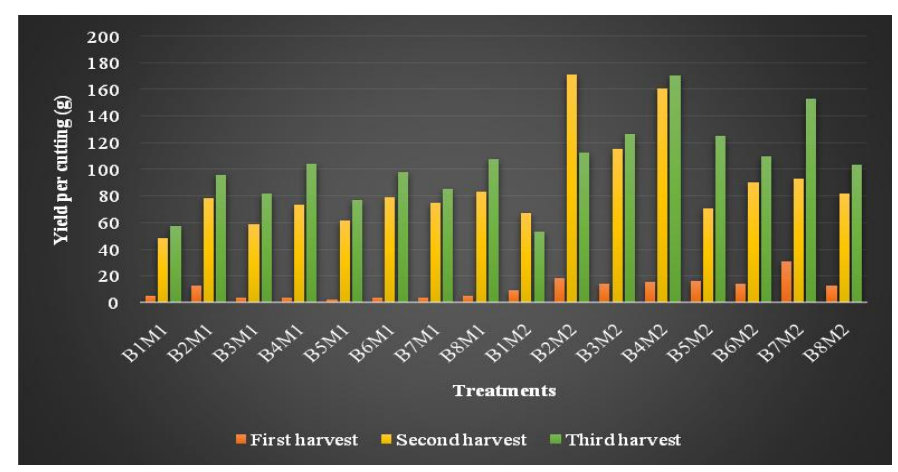

Sharma et al., (2017) confirmed that application of humic acid $30 \mathrm{ml}$ recorded highest plant height $(36.4 \mathrm{~cm})$ in french bean cv. Contender. The enhanced plant height caused by humic acid might be due to improved nutrient uptake which favours better growth. This result fall in line with the findings of Donnell (1973), who stated that increased plant height of sunflower due to humic acid application which is attributed to better rooting and adsorption of nutrients by plants and also due to the auxin type of activity of humic acid on plant growth. Leaves per plant were highest for vermiwash when applied at 3\% through wick fertigation. Ansari (2008) stated that growth parameters and yield of spinach and onion was significantly higher in plots treated with vermiwash. Application of humic-fulvic acid mixture @ $3 \%$ through foliar application significantly increased the leaf length as well as leaf width. This is in agreement with Ugur et al., (2013), who claimed that humic substances generally increase the growth and quality of green vegetables. $0.4 \%$ humic acid increased the leaf length and leaf width in rocket plants. Length of root was higher humic acid @ 3\% through foliar application followed by humic - fulvic acid mixture@3 $\%$ through foliar application. This result fall in line with Borcioni et al., (2016), who claimed that humic substances are used to promote plant growth, especially of the root system in lettuce. Late bolting was observed inhumic acid @3\% and humic-fulvic acid mixture@3\% through foliar application. This may be attributed by humic substances which reduce stress for moisture and higher 
nutrient contents of the component (Khaled and Fawy, 2011).

Among the biostimulants leaf/stem ratio was highest for salicylic acid @ 50mg L $\mathrm{m}^{-1}$ through wick fertigation. In a different experiment Y1ldirim and Dursun (2009), found highest yield of tomato at $0.5 \mathrm{mM}$ salicylic acid treatment. Khandaker et al., (2011) also supported the result. According to their study low dose $\left(10^{-5} \mathrm{M}\right)$ foliar application of salicylic acid is effective than higher doses in improving growth parameters and yield of red amaranth. In the present study, yield per plant was higher for humic-fulvic acid mixture @ 3 $\%$ through foliar application. This result is in agreement with Huseinet al., (2015) and kumar et al., (2015), in which higher yields were obtained in spraying plants with humic and fulvic substances in tomato and okra. During the course of study, the important biotic factors observed were leaf spot, and leaf webber.

In conclusion the biostimulantsand foliar method of application was found to be effective for improving growth, yield and quality of amaranthus in growbag organic cultivation. Among the biostimulants, humic - fulvic acid mixture @ 3\% produced the highest plant height, leaf length, leaf width, branches per plant, fresh weight of leaves, yield and $\mathrm{B}: \mathrm{C}$ ratio (1.35) compared to control (0.22).

\section{References}

Abdalla, M.M. 2014. Boosting the growth of rocket plants in response to the application of Moringa oleifera extracts as a biostimulant. Life Sci. J. 11(11): 1113-1121.

Ansari, A. A. 2008. Effect of vermicompost and vermiwash on the productivity of spinach (Spinacia oleracea), onion (Allium cepa) and potato (Solanum tuberosum). World J. Agric. Sci. 4(5): 554-557.

Borcioni, E., Mogor, A. F., and Pinto, F. 2016. Influence of the application of fulvic acid on seedling root growth and yield in lettuce. Riv. Ciencia Agron. 47(3): 509-515.

DES. [Department of Economics and Statistics]. 2017.Agricultural statistics. Department of Economics and Statistics, Government of Kerala. 34p.

Ferrarezi, R.S. and Testezlaf, R. 2016. Performance of wick irrigation system using self-compensating troughs with substrates for lettuce production. J. of Plant Nutr. 39(1):147-161.

Husein, M. E., El-Hassan, S. A., and Shahein, M. M. 2015. Effect of humic, fulvic acid and calcium foliar application on growth and yield of tomato plants. Int. J. Biosci. 7(1): 132-140.

Khaled, H. and Fawy, H. A. 2011. Effect of different levels of humic acids on the nutrient content, plant growth, and soil properties under conditions of salinity. Soil Water Res. 6(1): 21-29.

Khandaker, L., Akond, A. M., and Oba, S. 2011. Foliar application of salicylic acid improved the growth, yield and leaf's bioactive compounds in red amaranth (Amaranthus tricolor). Veg. Crops Res. Bull. 74: 77-86.

Kumar, P., Rana, D. K., Singh, V., and Shah, N. 2015. Effect of humic acid on growth, yield and quality of okra (Ablemoschus esculantus (L.) Moench) cv. Arka Anamika under subtropical conditions of Garhwal Himalaya. Int. J. Innov. Res. Sci. Technol. 1: 2349-6010.

O'donnell, R. W. 1973. The auxin-like effects of humic preparations from leonardite. Soil Sci. 116(2): 106-112.

Sharma, D., Rana, D. K., Shah, K. N., and Singh, V. 2017. Effect of various concentrations of bio-regulators and humic acid on growth, yield and quality 
of French bean (Phaseolus vulgaris L.) cv. contender under subtropical condition of Garhwal hills. Plant Arch. 17(1): 647-650.

Sundararasu, K. 2016. Effect of vermiwash on growth and yielding pattern of selected vegetable crop Chilli (Capsicum annuит). Int. J. Adv. Res. Biol. Sci. 3(9): 155-160.

Taha, A.A., Omar, M.M., and Ghazy, M.A. 2016. Effect of humic and fulvic Acids on growth and yield of lettuce plant. J. Soil Sci. and Agric. Eng. 7(8): 517-522.

Ugur, A., Demİrtas, B., Caglar, S., Zambİ, O., and Turkmen, M. 2013. Effect of humic acid application on yield and quality in green vegetables. In Proceedings of the 24th International Scientific-ExpertConference of Agriculture and Food Industry, 25-28 September 2013, Bosnia. Faculty of Agriculture and Food Sciences, University of Sarajevo, pp. 381-385.

Yıldırım, E. and Dursun, A. 2009. Effect of foliar salicylic acid applications on plant growth and yield of tomato under greenhouse conditions. Acta Hort. 807: 395-400.

\section{How to cite this article:}

Sherinlincy, A., M. Rafeekher and Sarada, S. 2020. Evaluation of Biostimulants in Growbag Culture of Organic Amaranthus (Amaranthus tricolor L.). Int.J.Curr.Microbiol.App.Sci. 9(12): 2916-2922. doi: https://doi.org/10.20546/ijcmas.2020.912.346 